\title{
Prediction and Control Model of Carbon Emissions from Thermal Power Based on System Dynamics
}

\author{
Xueke Bao, Tian Xie*, Hainan Huang \\ School of Economics, Management and Law, University of South China, Hengyang 421000, China
}

Received: 23 December 2020

Accepted: 8 April 2021

\begin{abstract}
Thermal power is the main part in China's energy structure of power industry. Because of huge carbon emissions and relatively high energy consumption, thermal power has been listed as an important industry for energy conservation and emission reduction. Therefore, the growth rate, carbon emissions growth peak and developing trend of China's thermal power are modeled and simulated based on System Dynamics. With three scenarios set up, so as to explore the impact of the economic development, optimization of power structure and improve CCS technology and adjust national policy on carbon emissions thermal power industry in the future. The results show that, according to the current development trend, the total amount of carbon emissions in thermal power industry will reach a peak of 4.228 billion $t$ in 2026. At the same time, there is a significant positive correlation between economic development and thermal power carbon emissions. The current best and fastest way for China is reducing the proportion of thermal power generation and increasing the proportion of non-fossil power generation. The widespread use of the CCS technology will also greatly reduce thermal power carbon emissions. The simulation results of this paper provide the Chinese government with suggestions for carbon emissions reduction, power structure determination, the long-time development of thermal power.
\end{abstract}

Keywords: thermal power development, carbon emissions, System Dynamics, energy conservation and emission reduction

\section{Introduction}

Nowadays, sustainable development and global warming are still the main issues of social development [1]. Global warming directly leads to sea level rise, temperature rise, extreme weather and other severe phenomena. These phenomena not only seriously affect the earth's environment, natural resources and human

*e-mail: thanksky@163.com security, but also pose great challenges to human survival and development, and at the same time threaten the sustainable development of the entire human society [2-3]. In 2014, the fifth assessment report of the Intergovernmental Panel on Climate Change (IPCC) pointed out that the massive emissions of greenhouse gases have led to many climate changes including global warming. The total global carbon emissions have increased from 9.434 billion tons in 1961 to 34.649 billion tons in 2011 [4]. The number may continue to increase by one to two times if no effective 
measures are taken to control it in time. During the 2019 World Climate Conference in Copenhagen, the Chinese government made a commitment to reduce carbon dioxide emissions per unit of GDP by $40 \%$ to $45 \%$ by 2020 compared with 2005, China's task of emission reduction is urgent [5].

China is the world's largest energy consumer. Large amounts of energy consumption lead to massive carbon dioxide emissions. The $\mathrm{CO}_{2}$ emissions from the power industry are the most important source of the total amount of carbon emissions from the energy industry [6]. The power is not only the most important basic energy industry to ensure the development of the national economy, but also the key to realize the global energy transformation and climate control goals in the future [7-8]. Thermal power is an irreplaceable basic power source in China. Due to China's energy structure of "rich in coal, poor in oil and less in gas" and the distribution characteristics of natural resources, thermal power has been occupying the absolute main position in China's power production field for a long time, which plays the role of "pillar" and "ballast stone" [9], and will continue to play an irreplaceable role, and its status as the absolute main power source and basic power source for China's power supply will not change [10]. In view of the power generation scale of thermal power enterprises, it is not difficult to imagine the large amount of $\mathrm{CO}_{2}$ emissions. However, the current high environmental protection requirements do not allow thermal power generation to continue to take the extensive development road, and the sustainable development road and low-carbon economic road have become the only way for thermal power generation enterprises [11]. Faced with the pressure of improving air quality and achieving energy conservation and emission reduction, the Chinese government has introduced a series of policies to achieve sustainable development of thermal power. China's past power development policies have resulted in overinvestment in thermal power installed capacity and low operating efficiency [12]. With the increasing awareness of energy conservation and emission reduction, the Chinese Council has issued a number of policies to guide the transition of coal-fired power generation to efficient and low-carbon power generation [13]. Generally speaking, China's thermal power industry has a bright future. However, on the other hand, China's thermal power development will still be limited, the coal burning emissions too much carbon dioxide with low energy efficiency, and coal prices continuously rise and so on [14]. In order to promote the development of thermal power, some scholars have suggested that China should focus on strengthening the development of CCS technology and its widely application in thermal power plants, accelerating the development of clean thermal power [15-16]. The above mainly focuses on the development of thermal power in China using qualitative methods such as policy analysis, charts and paired comparison. Therefore, there is a lack of researches on quantitative assessment of thermal power trends. System Dynamic (SD) can not only simulate the real happening in the market, but also correctly explain the relationship between the main variables of the system [17]. SD models have also been extensively developed to explore the effects of energy consumption and emission reduction policies [18-20]. Some scholars have used SD method to study the development of China's thermal power and energy industries [21]. The SD approach has been considered in the sustainable management of power systems, but has not been mentioned in the forecast of thermal power development under China's new low-carbon development strategy. Previous studies have not taken the complex feedback of CCS technology and policy investment into account, and few studies have included CCS technology as a variable in thermal power systems. Studies have shown that CCS can effectively capture and store about 90 percent of carbon dioxide. Therefore, CCS technology plays an indispensable role in the sustainable development of thermal power [22]. The development of thermal power is a complex dynamic evolution process involving many fields, so it has obviously nonlinear characteristics. By analyzing economic development, power structure and CCS technology, policy investment and other factors, we have established an integrated SD model to pursue the future development path of thermal power in China.

Considering its integrity and dynamic advantages, the emerging CCS technology and low-carbon policies are incorporated into the thermal power industry system dynamics model, and the role of carbon dioxide emission reduction in China's thermal power industry under different scenarios is obtained through scenario dynamic simulation, and the peak time of China's thermal power carbon emissions under different scenarios is predicted, which will provide reference for China's future large-scale development of CCS technology in thermal power industry.

\section{Study Areas}

Although China's renewable energy development momentum is strong, thermal power generation still accounts for about $70 \%$ of China's total power generation and is the main source of China's $\mathrm{CO}_{2}$ emissions [23]. This means that the thermal power industry must take timely and effective measures to speed up the transformation to a low-carbon economic development model. However, judging from the current social development in China, to ensure sufficient power supply, it still need to rely on the support of the thermal power industry. For a long period of time to come, thermal power still has incomparable technical and economic advantages in ensuring reliable supply of electricity and heat and clean and efficient utilization of coal. The "ballast stone" function of thermal power cannot be replaced [24]. However, the thermal power industry is facing severe challenges due to multiple contradictions such as the sharp rise in the cost of 
coal fuel and the heavy task of energy conservation and emission reduction transformation [25]. In order to promote the sustainable development of the thermal power generation industry and realize China's $\mathrm{CO}_{2}$ emission reduction commitment as soon as possible, some scholars have proposed to fundamentally change the power generation technology of thermal power plants, improve energy utilization efficiency, upgrade energy infrastructure, optimize the development of clean and efficient coal and electricity, and reduce carbon dioxide emissions from thermal power, which are the main directions for the transformation and development of the thermal power industry [26].

\section{Materials and Methods}

\section{Causal Feedback Analysis and Stock Flow Chart}

Factors affecting carbon emissions from thermal power mainly include economy, technology, energy environment and national policies. In this paper, the carbon emission system of thermal power industry is divided into three subsystems: technology and economy, energy environment and social policy [27-31]. As can be seen from Fig. 1, there is a complex causal relationship among the technical and economic subsystems, the energy and environment subsystems and the social policy subsystems. The national economic development has promoted the growth of electricity consumption in various industries, and the growth of electricity consumption in various industries has led to an increase in electricity generation. Due to China's resource situation, China's power generation structure is still dominated by thermal power to ensure reliable power supply, which will inevitably lead to an increase in thermal power generation, thus causing energy consumption and environmental changes. Environmental changes force human beings to invest more emission reduction costs, thus further affecting economic development. The interaction between the three systems forms a complex and dynamic process, and continuous cyclic adjustment makes the system run stably. Based on literature [32-34], this paper determines the influencing factors of carbon emissions in the thermal power industry and constructs three subsystems. The specific indicators in the subsystems are as follows:

Technical and economic subsystem: GDP, primary industry output value, proportion of primary industry output value, technology investment, environmental protection investment, government R\&D investment, CCS technology ratio, etc.

Energy and environment subsystems: net coal consumption rate, coal consumption, natural gas consumption, proportion of thermal power, thermal

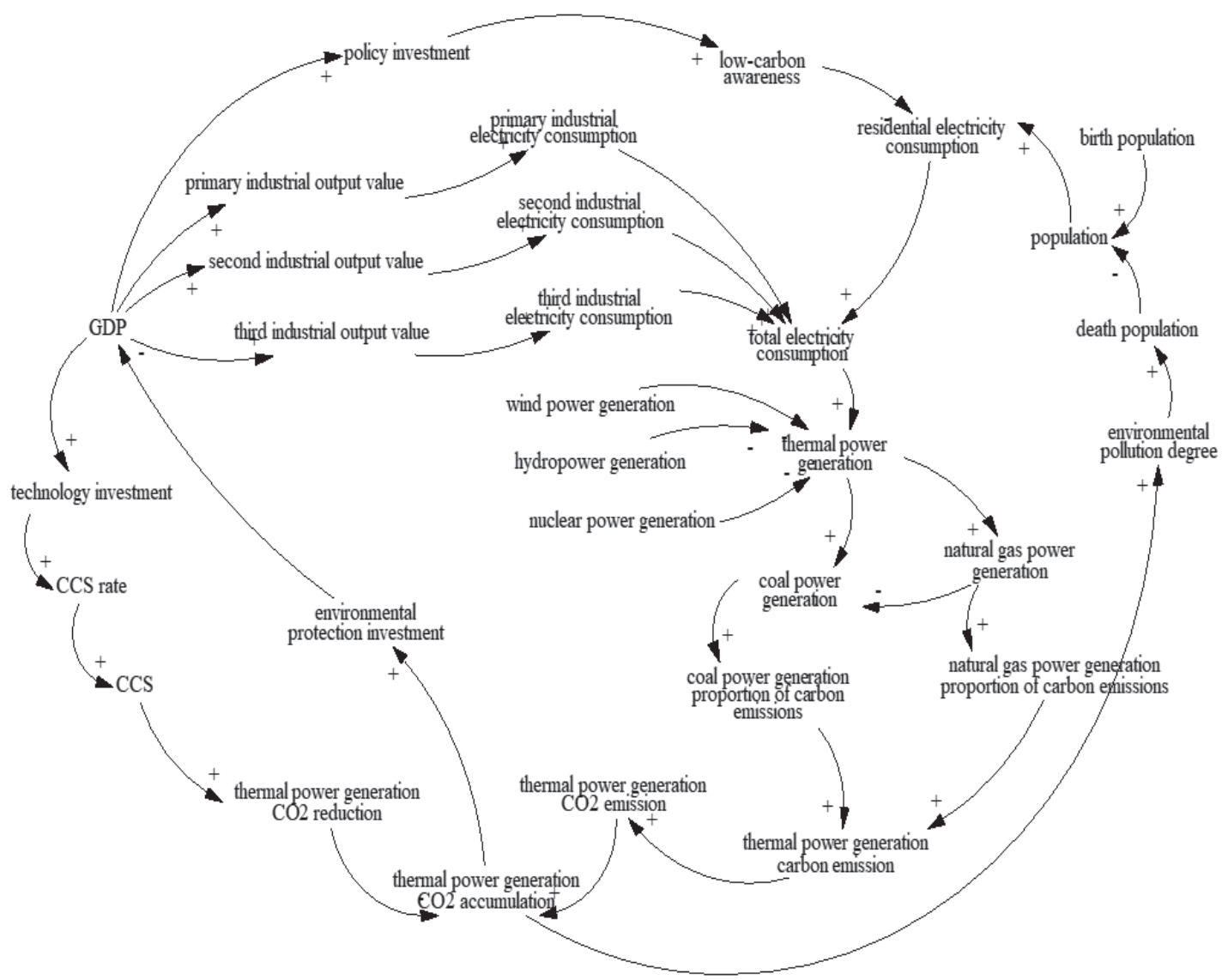

Fig. 1. Causal loop diagram of carbon emission in Thermal power industry. 


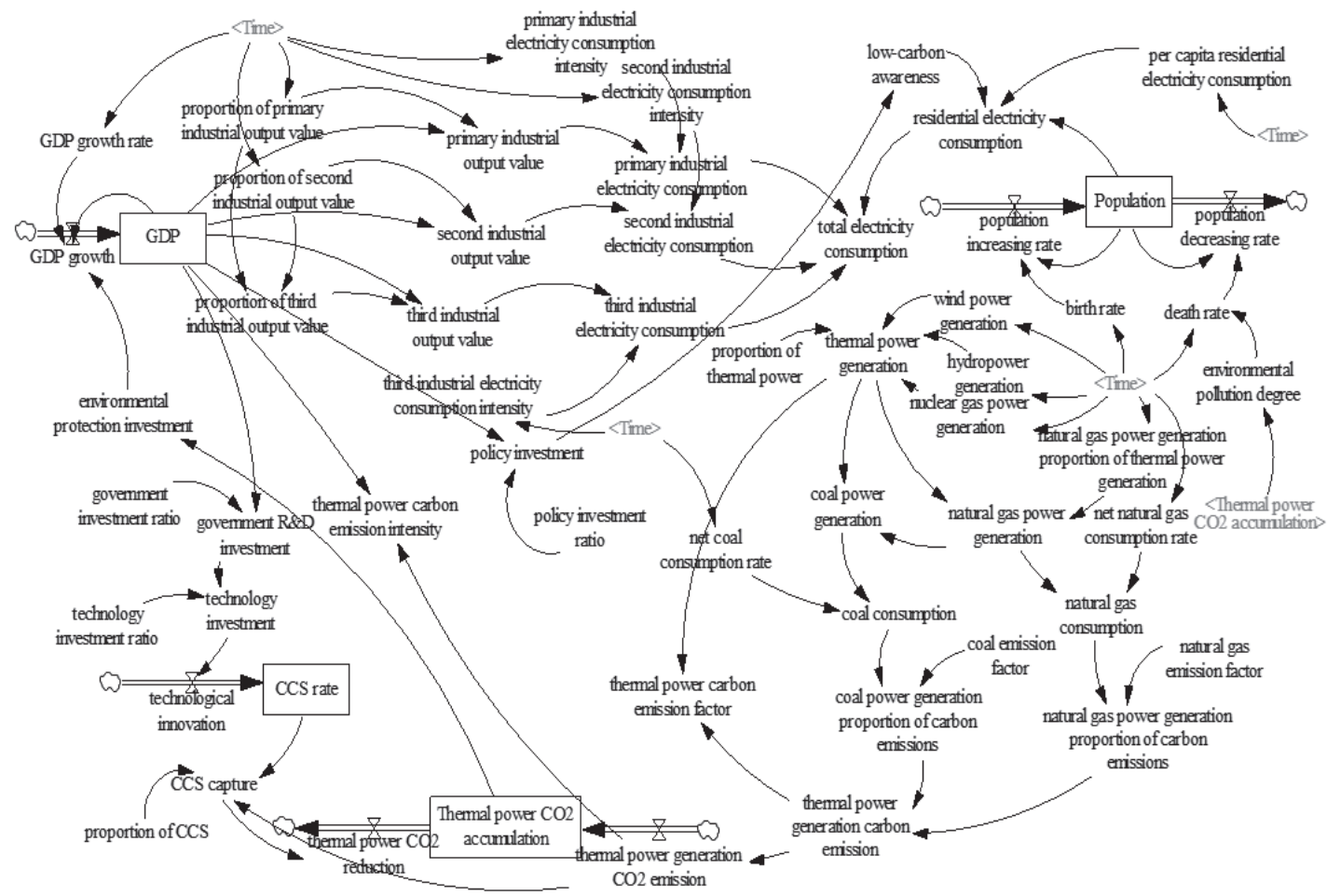

Fig. 2. Stock flow diagram of carbon emission system in the Thermal power industry, we can clearly understand the relationship between the variables within the pyroelectric carbon emission system.

power, wind power, nuclear power, $\mathrm{CO}_{2}$ emissions from thermal power industry, cumulative $\mathrm{CO}_{2}$ emissions from thermal power industry, etc.

Social policy subsystem: policy investment, lowcarbon awareness, per capita residential electricity consumption, etc.

Based on the drawing of the above causal loop diagram, the stock flow diagram shown in Fig. 2 is drawn by comprehensively considering the carbon emissions generated by thermal power in the power generation process and many factors such as the output value of the three industries and the proportion of GDP in the three industries, coal consumption for power supply, $\mathrm{CO}_{2}$ emissions from thermal power generation, cumulative $\mathrm{CO}_{2}$ emissions from thermal power generation, etc.

\section{Data Sources}

According to the relationship between the variables in the above stock flow diagram, China's thermal power carbon emissions are simulated. In this paper, the historical data of the output value of each industry and the proportion of each industry in GDP are mainly obtained from the China Statistical Yearbook [35-39]. The coal consumption and natural gas consumption are mainly obtained from the China Energy Statistical Yearbook [40-41]. The coal carbon emission coefficient and natural gas carbon emission coefficient refer to the carbon emission coefficient published by IPCC [42]. GDP growth rate, birth rate, the proportion of natural gas power generation in thermal power generation, coal consumption for power supply, etc. are all expressed by With Lookup Function method. In addition, this paper also uses logical function method. In this paper, the With Lookup Function data from 2000 to 2017 are all from China Statistical Yearbook [35-39], and the data from 2017 to 2025 are based on the current development forecast of China.

\section{Model Simulation}

The main model equations are as follows:

$$
\begin{gathered}
G D P=\operatorname{INTEG}(\text { GDP growth }, 100280) \\
P D R=P o P^{*} D R^{*}(1+E P D)
\end{gathered}
$$

$L C A=P I / 2.35615 e^{*} P U L S E(2020,20)$

$R E C=P E C^{*} P o p$

$N A P G=N G C * N G E F / 10000 * 44 / 12$

$$
C C S \text { rate }=I N T E G(T I, 0.85)
$$

$$
P I O V=G D P^{*} P P I O V
$$

$N G E F=0.4483$ 
$P o p=I N T E G(P I R-P D R, 12.6743)$

$$
T I=G I^{*} T I R
$$

\section{$T P I=T P G / G D P$}

$E P I=T P A * 1.25 e-005$

$$
P I E C=P I O V^{*} P I E C I
$$

Proportion of $C C S=0.02$

Letter comparison table is shown in Table 1.

According to the above parameters and model equations, the above variables, their interrelations and

Table 1. To make the formula look more appropriate, use specific letters instead of sentence in the formula. Table 1 is a letter

\begin{tabular}{|c|c|}
\hline Special letter & Sentence \\
\hline PDR & Population decreasing rate \\
\hline Pop & population \\
\hline DR & Decreasing rate \\
\hline EPD & Environmental pollution degree \\
\hline LCA & Low carbon awareness \\
\hline PI & Policy investment \\
\hline REC & Residential electricity consumption \\
\hline PEC & Per capita electricity consumption \\
\hline NAPG & $\begin{array}{c}\text { Natural gas power generation proportion of } \\
\text { carbon emission }\end{array}$ \\
\hline NGC & Natural gas consumption \\
\hline NGEF & Natural gas emission factor \\
\hline NGEF & Natural gas emission factor \\
\hline PIR & Population increasing rate \\
\hline TI & Technology investment \\
\hline GI & Government investment \\
\hline TIR & Technology investment ratio \\
\hline TPI & Thermal power carbon emission intensity \\
\hline TPG & Thermal power generation $\mathrm{CO}_{2}$ emission \\
\hline EPI & Environment protection investment \\
\hline TPA & Thermal power $\mathrm{CO}_{2}$ accumulation \\
\hline PIOV & Primary industry output value \\
\hline PPIOV & Proportion of primary industry output value \\
\hline PIEC & Primary industry electricity consumption \\
\hline PIECI & $\begin{array}{l}\text { Primary industry electricity consumption } \\
\text { intensity }\end{array}$ \\
\hline
\end{tabular}
comparison table. the values of the parameters are input into the system dynamics software Vensim, and the emulation results are shown in Table 2.

After the model parameters and model equations are set, the model is simulated by the system dynamics software Vensim-PLE to obtain the target value. In this paper, the validity of the model will be tested from three aspects: visual inspection, historical test and stability test, thus proving the authenticity of the model.

1) Visual inspection. Visual inspection is to test the correctness of variable definition, causality, process structure, functional relationship and dimension of the system model by analyzing the data. Based on the comprehensive consideration of economy, population, thermal power generation, carbon emission intensity and other aspects of thermal power carbon emission system, the scientific method is used to analyze it, and the model test and unit test pass in Vensim software operation process, which shows that the causal relationship in this model is reasonable and the dimension is consistent, and it can accurately reflect the operation process of carbon emission system in thermal power industry.

2) Historical test. After the model design is completed, its effectiveness needs to be tested through model debugging. All the parameters involved in the model in this paper are consistent with the reality as far as possible, and the parameters in the model are repeatedly modified and adjusted in combination with the actual data. Therefore, the parameters set in this paper are in line with the actual situation. The model in this paper selects historical data with overall situation and representative variables, and simulates the data from 2000 to 2017. The results are shown in Table 3. Historical test results show that the relative errors are all controlled within- $10 \%$ to $10 \%$. Therefore, the simulation results of this model basically conform to the actual development of China's thermal power carbon emissions. In general, the SD model in this paper has good simulation capability and can accurately reflect the development trend of carbon emissions in China's thermal power industry under the changing policy and economic environment.

3) Stability test. In order to test the overall stability of the model, three asynchronous simulation values of 0.25 years, 0.5 years and 1 year are selected for operation test. The simulation results are shown in Fig. 3. It can be seen that when the simulation step size changes, the final results of the model have not been greatly changed, indicating that the model is stable and feasible.

\section{Scenario Analysis and Dynamic Simulation}

This paper will use scenario analysis method to predict the future development trend of China's thermal power carbon emissions and observe the changes of thermal power carbon emissions. Scenario analysis is a kind of scenario analysis method, change the parameters 
Table 2. In order to test the validity and authenticity of the model, the values of GDP, Population, Thermal power generation, thermal power generation carbon emissions variables from 2000 to 2017 were simulated according to the established system dynamics model.

\begin{tabular}{|c|c|c|c|c|}
\hline Year & $\mathrm{GDP} /\left(10^{8}\right.$ Yuan $)$ & Population $/\left(10^{8}\right)$ & Thermal power generation $/\left(10^{8} \mathrm{kwh}\right)$ & $\begin{array}{l}\text { thermal power generation carbon } \\
\text { emissions / }\left(10^{4} \mathrm{t}\right)\end{array}$ \\
\hline 2000 & 100280 & 12.6743 & 10859.4 & 10.7879 \\
\hline 2001 & 110863 & 12.7704 & 11589.4 & 11.3143 \\
\hline 2002 & 121717 & 12.8642 & 12989.1 & 12.4776 \\
\hline 2003 & 137422 & 12.9472 & 15583.7 & 14.7314 \\
\hline 2004 & 161840 & 13.025 & 17661.7 & 16.4018 \\
\hline 2005 & 187319 & 13.1013 & 20240.6 & 18.4743 \\
\hline 2006 & 219438 & 13.1785 & 23485.5 & 21.0682 \\
\hline 2007 & 270092 & 13.2481 & 27490.3 & 24.2241 \\
\hline 2008 & 319244 & 13.3166 & 28237 & 24.402 \\
\hline 2009 & 348517 & 13.3842 & 30083 & 25.5143 \\
\hline 2010 & 412119 & 13.4494 & 33545.2 & 27.8998 \\
\hline 2011 & 487940 & 13.5138 & 38356 & 31.3202 \\
\hline 2012 & 538579 & 13.5786 & 38952.9 & 31.1357 \\
\hline 2013 & 592962 & 13.6458 & 41742.3 & 32.7014 \\
\hline 2014 & 641280 & 13.7129 & 42000.1 & 32.1899 \\
\hline 2015 & 685992 & 13.7844 & 40948.5 & 30.7004 \\
\hline 2016 & 740060 & 13.8527 & 43194 & 31.6709 \\
\hline 2017 & 820753 & 13.9339 & 46131.4 & 33.0829 \\
\hline 2018 & 900308 & 14.0069 & 48929.2 & 34.3056 \\
\hline
\end{tabular}

\section{thermal power generation carbon emission}

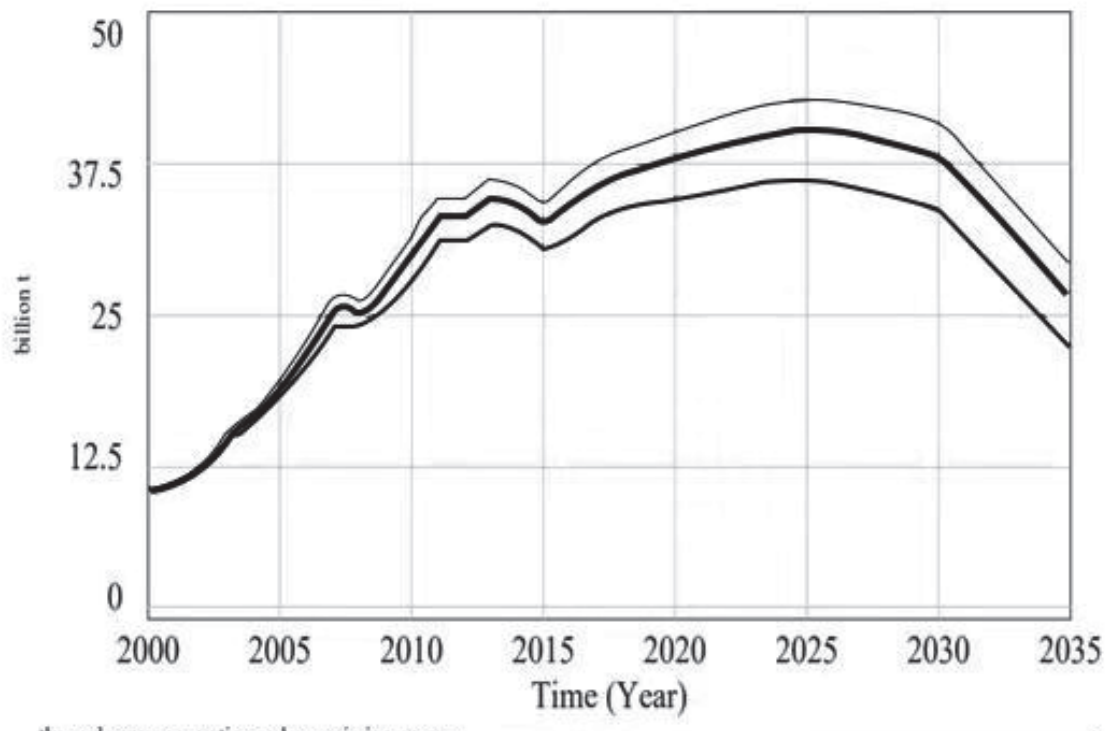

thermal power generation carbon emission : year

thermal power generation carbon emission : half a year

thermal power generation carbon emission : quarter

Fig. 3. In order to test the overall stability of the model, three asynchronous simulation values of 0.25 years, 0.5 years and 1 year are selected for operation test. The result shows that when the simulation step size changes, the final results of the model have not been greatly changed, indicating that the model is stable and feasible. 
Table 3. The simulated value and historical value of GDP, Population, Thermal power generation, thermal power generation carbon emissions variable are compared, and the relative errors are all controlled within $-10 \%$ to $10 \%$. The results show that the simulation results of this model basically conform to the actual development of China's thermal power carbon emissions. The SD model in this paper has good simulation capability and can accurately reflect the development trend of carbon emissions in China's thermal power industry under the changing policy and economic environment.

\begin{tabular}{|c|c|c|c|}
\hline \multirow{2}{*}{ Year } & \multicolumn{3}{|c|}{$\mathrm{GDP} /\left(10^{8}\right.$ Yuan $)$} \\
\hline & True Value & Simulation & Error $(\%)$ \\
\hline 2000 & 100280.1 & 100280 & 0.01 \\
\hline 2001 & 110863.1 & 110863 & 0.00009 \\
\hline 2002 & 121717.4 & 121717 & 0.00033 \\
\hline 2003 & 137422 & 137422 & 0 \\
\hline 2004 & 161840.2 & 161840 & 0.00012 \\
\hline 2005 & 187318.9 & 187319 & 0.00005 \\
\hline 2006 & 219438.5 & 219438 & 0.00023 \\
\hline 2007 & 270092.3 & 270092 & 0.00011 \\
\hline 2008 & 319244.6 & 319244 & 0.00019 \\
\hline 2009 & 348517.7 & 348517 & 0.00020 \\
\hline 2010 & 412119.3 & 412119 & 0.00007 \\
\hline 2011 & 487940.2 & 487940 & 0.00004 \\
\hline 2012 & 538580 & 538579 & 0.00019 \\
\hline 2013 & 592963.2 & 592962 & 0.00020 \\
\hline 2014 & 641280.6 & 641280 & 0.00009 \\
\hline 2015 & 685992.9 & 685992 & 0.00013 \\
\hline 2016 & 740060.8 & 740060 & 0.00011 \\
\hline 2017 & 820754.3 & 820753 & 0.00016 \\
\hline \multirow{2}{*}{ Year } & \multicolumn{3}{|c|}{ Population / $\left(10^{8}\right)$} \\
\hline & True Value & Simulation & Error $(\%)$ \\
\hline 2000 & 100280.1 & 100280 & 0.01 \\
\hline 2001 & 110863.1 & 110863 & 0.00009 \\
\hline 2002 & 121717.4 & 121717 & 0.00033 \\
\hline 2003 & 137422 & 137422 & 0 \\
\hline 2004 & 161840.2 & 161840 & 0.00012 \\
\hline 2005 & 187318.9 & 187319 & 0.00005 \\
\hline 2006 & 219438.5 & 219438 & 0.00023 \\
\hline 2007 & 270092.3 & 270092 & 0.00011 \\
\hline
\end{tabular}

\begin{tabular}{|c|c|c|c|}
\hline 2008 & 319244.6 & 319244 & 0.00019 \\
\hline 2009 & 348517.7 & 348517 & 0.00020 \\
\hline 2010 & 412119.3 & 412119 & 0.00007 \\
\hline 2011 & 487940.2 & 487940 & 0.00004 \\
\hline 2012 & 538580 & 538579 & 0.00019 \\
\hline 2013 & 592963.2 & 592962 & 0.00020 \\
\hline 2014 & 641280.6 & 641280 & 0.00009 \\
\hline 2015 & 685992.9 & 685992 & 0.00013 \\
\hline 2016 & 740060.8 & 740060 & 0.00011 \\
\hline 2017 & 820754.3 & 820753 & 0.00016 \\
\hline \multirow{2}{*}{ Year } & \multicolumn{3}{|c|}{ Thermal power generation $/\left(10^{8} \mathrm{kwh}\right)$} \\
\hline & True Value & Simulation & Error (\%) \\
\hline 2000 & 11142 & 10859.4 & 2.54 \\
\hline 2001 & 11767.5 & 11589.4 & 1.51 \\
\hline 2002 & 13273.8 & 12989.1 & 2.145 \\
\hline 2003 & 15803.6 & 15583.7 & 1.39 \\
\hline 2004 & 17955.9 & 17661.7 & 1.64 \\
\hline 2005 & 20473.4 & 20240.6 & 1.14 \\
\hline 2006 & 23696 & 23485.5 & 0.89 \\
\hline 2007 & 27229.3 & 27490.3 & -0.96 \\
\hline 2008 & 27900.8 & 28237 & -1.205 \\
\hline 2009 & 29827.8 & 30083 & -0.86 \\
\hline 2010 & 33319.3 & 33545.2 & -0.68 \\
\hline 2011 & 38337 & 38356 & -0.049 \\
\hline 2012 & 38928.1 & 38952.9 & -0.064 \\
\hline 2013 & 42470.1 & 41742.3 & 1.71 \\
\hline 2014 & 42686.5 & 42000.1 & 1.61 \\
\hline 2015 & 42841.9 & 40948.5 & 4.42 \\
\hline 2016 & 44371 & 43194 & 2.653 \\
\hline 2017 & 46627 & 46131.4 & 1.063 \\
\hline
\end{tabular}

of one or more influencing factors, use Vensim software to carry out simulation, compare with the set target values, and analyze the influence of the changes of the influencing factor parameters on other variables in the model through the set different scenarios, so that decision makers and the government can put forward constructive opinions accordingly. The initial life of the model in this paper is set to 2017, and the final year of simulation is 2035 . Because the thermal power system is a huge system that changes with time and is affected by many factors, this paper only selects GDP growth rate, birth rate, mortality rate, power generation structure, technology and policy investment ratio as regulatory variables. Among them, the GDP growth rate, birth rate and mortality rate are all predicted according to the $13^{\text {th }}$ Five-Year Plan Outline for National Economic and Social Development, and the power structure is predicted according to the Outlook 2030 China 
Table 4. Some key parameters values in three scenarios.

\begin{tabular}{|c|c|c|c|c|}
\hline Parameter & Unit & Benchmark scenario & Energy saving scenario & Super energy saving scenario \\
\hline GDP growth rate & $\%$ & Decreasing volatility yearly & With benchmark scenario & With energy saving scenario \\
\hline Increasing rate & $\%$ & $1.3 \%$ fluctuations & With benchmark scenario & With energy saving scenario \\
\hline Decreasing rate & $\%$ & $7.1 \%$ fluctuations & With benchmark scenario & With energy saving scenario \\
\hline Technology investment ratio & Dmnl & Increase yearly & $\begin{array}{c}\text { With benchmark scenario } \\
\text { Slightly higher }\end{array}$ & With energy saving scenario \\
\hline Government investment ratio & Dmnl & Increase yearly & $\begin{array}{c}\text { With benchmark scenario } \\
\text { Slightly higher }\end{array}$ & With energy saving scenario \\
\hline
\end{tabular}

Energy Report [43-44]. With Vensim-PLE tool, through repeated operation and debugging, this paper sets that besides the benchmark scenario, there are energysaving scenario and super-energy-saving scenario, both of which can promote economic development, improve the ecological environment and reduce the carbon emission of thermal power [45-46]. However, in the development process, the measures taken by the two scenarios are different, so there is a certain gap in the achieved results. Each scenario is described as follows:

Benchmark scenario. The benchmark scenario is not to take any targeted measures under the full consideration of China's current energy conservation and emission reduction measures. Under this scenario, China economic development has changed to some extent with the prediction of experts, but the power structure, CCS technology level and national policy investment have not changed substantially.

Energy saving scenario. The energy-saving scenario is that all countries in the world reach a consensus on the issue of climate change. Based on a comprehensive analysis of China's domestic economic development situation, environmental protection capability and technical level capability, coupled with foreign technology transfer and financial assistance, the scenario is set as a decline in the proportion of thermal power, while non-fossil energy industries such as wind power, hydropower and nuclear power accelerate their development and form a certain scale. At the same time, the penetration rate of CCS technology in the thermal power industry is increasing year by year, and the proportion of national policy investment is also increasing.

Super-energy-saving scenario. The superenergy-saving scenario means that with the support of the international community in terms of capital and technology, China's energy-saving and emissionreduction actions have gone further. In this scenario, China can obtain high-quality resources in the world, speed up the pace to reduce the proportion of thermal power, promote the development of wind, water, nuclear and other power industries, and develop China's power generation structure in depth. At the same time, greater breakthroughs have been made in key technical levels [47]. CCS technical level has been greatly improved and is widely used in the thermal power industry [48-51]. In addition to technology, national policies are also more effective. People's awareness of low carbon is gradually increasing. China's energy conservation and

Table 5. Based on the development trend of China, assume baseline scenario, energy-saving scenario, super-energy-saving scenario to predict to predict the development of China's thermal power carbon emission from the aspects of economic, population, power structure, technology and policy.

\begin{tabular}{|c|c|c|c|c|}
\hline \multirow{2}{*}{ Indicator } & Energy saving scenario & Benchmark scenario & Super energy saving scenario \\
\hline \multirow{2}{*}{ Economy } & GDP increase rate $\%$ & 6 & 7 & 8 \\
\hline \multirow{3}{*}{$\begin{array}{c}\text { Electric power } \\
\text { structure }\end{array}$} & Birth rate/\% & 12 & 73 & 7.5 \\
\cline { 2 - 5 } & Mortality rate/\% & 6.5 & 60 & 40 \\
\cline { 2 - 5 } & Thermal power ratio $\%$ & 50 & 6 & 20 \\
\cline { 2 - 5 } & Nuclear power ratio $\%$ & 12 & 4 & 23 \\
\hline \multirow{2}{*}{\begin{tabular}{c} 
Technology \\
\cline { 2 - 5 }
\end{tabular}} & $\begin{array}{c}\text { CCS technology } \\
\text { investment ratio } \%\end{array}$ & 0.05 & 11 & 0.02 \\
\hline Policy & Policy investment ratio $\%$ & 0.06 & 0.025 & 0.09 \\
\hline
\end{tabular}


emission reduction effects are remarkable. China will also continue to move towards the planned goals.

Based on the setting of benchmark scenario, energysaving scenario and super-energy-saving scenario, and according to the actual situation of China's thermal power industry system, this paper selects GDP growth rate, birth rate, mortality rate, power structure, technology and policy investment ratio as regulatory variables. some key parameters values in three scenarios are obtained as shown in Table 4. Vensim software is used for repeated debugging and operation, and the index values of different parameters under each scenario are obtained as shown in Table 5.

\section{Results}

Based on the setting of the above different scenario parameters, the thermal power carbon emissions are simulated and the trend chart of thermal power carbon emissions is obtained. As shown in Fig. 4, the thickest line in the figure represents the benchmark scenario, the second thick line represents the energy-saving scenario, and the thinnest line represents the super-energy-saving scenario.

As can be seen from Fig. 4, in the three different scenarios, the thermal power carbon emissions will continue to grow in the next few years, but the thermal power carbon emissions in the energy-saving scenario are lower than the carbon emissions in the benchmark scenario, and the thermal power carbon emissions in the super-energy-saving scenario are lower than the carbon emissions in the energy-saving scenario. The peaks of thermal power carbon emissions in the three scenarios will all appear before 2030. The peak value of the benchmark scenario will appear in 2026, with a carbon emission of 4.228 billion tons; The peaks of thermal power carbon emissions in energy-saving scenarios and ultra-energy-saving scenarios will appear in 2025 and 2022 respectively, with carbon emissions of 3.609 billion tons and 3.468 billion tons respectively.

As can be seen from the trend Fig. 4, under the benchmark scenario, the $\mathrm{CO}_{2}$ emission from thermal power gradually increased from 3.308 billion tons in 2017 to a peak of 4.228 billion tons in 2026 and slowly decreases to 3.332 billion tons in 2035 . Under the energysaving scenario, the non-fossil energy power represented by wind power and nuclear power is increasing year by year. In addition to the improvement of CCS technology level, the peak value of $\mathrm{CO}_{2}$ emission from thermal power is advanced to 2025, with a peak level of 3.6 billion tons, and then drops to 2.253 billion tons in 2035. Under the super-energy-saving scenario, thanks to the strong support of national policies, wind power, hydropower, nuclear power and other non-fossil energy power have formed a certain scale. Combined with the influence of thermal power structure optimization and CCS technology, which are widely used in the

\section{thermal power generation carbon emission}

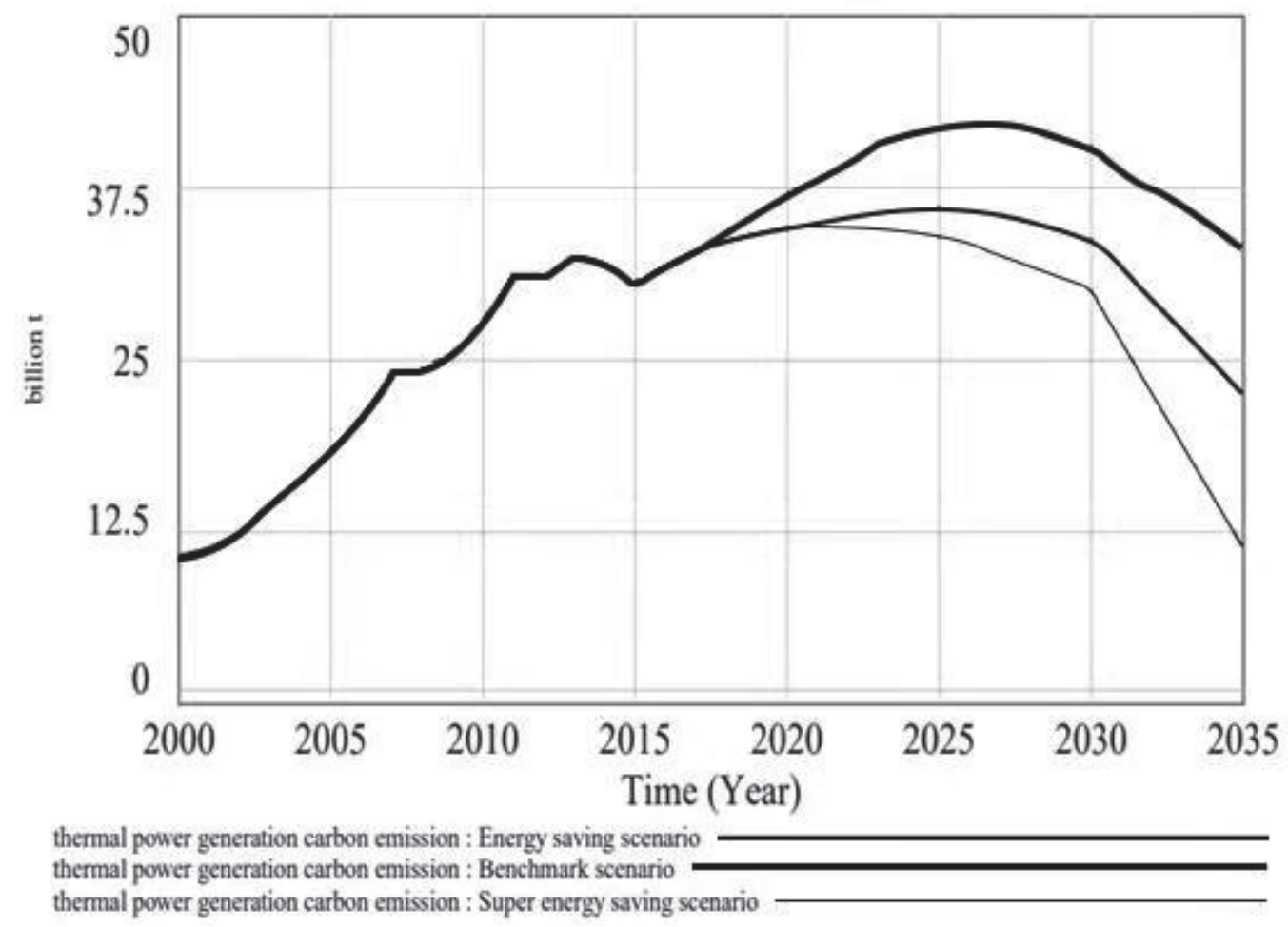

Fig. 4. Simulation results of different scenarios of thermal power generation carbon emissions, and it can be seen when the thermal power carbon emission peaks and the emission amount under different scenarios. 
thermal power industry and the improvement of energy utilization efficiency, the peak value of thermal power $\mathrm{CO}_{2}$ emissions has been advanced to the " $14^{\text {th }}$ Five-Year Plan" period, with a peak level of about 3.47 billion tons, and then drops rapidly to 1.133 billion tons in 2035, which is 2.199 billion tons less than the thermal power carbon emissions under the benchmark scenario, with an emission reduction effect of more than $50 \%$ and remarkable effect.

It can be seen from Fig. 5 that with the increase of technology investment and the in-depth promotion of low-carbon policy, the cumulative amount of carbon dioxide emissions from thermal power gradually slows down and decreases in three different scenarios. It also can be seen that the cumulative amount of superenergy-saving scenarios is the lowest, which indicates that technology investment and promotion of lowcarbon policies have played a certain role in thermal power carbon emissions, but the effect is not significant. This is mainly because the emerging technologies need to invest heavily at present, and China does not invest enough in technology. However, in order to achieve the goal of carbon neutrality quickly, the Chinese government will continue to introduce new emission reduction policies, research new emission reduction technologies and increase technology investment [5253]. Formulating new emission reduction schemes and mechanisms will inevitably have a huge impact on the carbon dioxide emission of thermal power industry.

To sum up, both energy-saving scenarios and superenergy-saving scenarios can fulfill China's emission reduction commitment to the thermal power industry. Therefore, no matter which scenario is adopted, it depends on the control strength of decision makers and the means of low-carbon development. In addition, under these two development scenarios, the carbon emission of thermal power in China will reach its peak before 2030, and the peak carbon emission of super energy-saving development scenario is 130 million tons less than that of energy-saving development scenario. This is because the adjustment speed of China's power structure and technology investment under the super energy-saving development scenario is faster than that under the energy-saving development scenario. However, compared with the energysaving development scenario, the ultra-energy-saving development scenario is a relatively radical development path for carbon emission reduction of thermal power, which requires the government to implement more radical carbon emission reduction measures, which may bring certain economic development pressure and is not conducive to the realization of China's overall social development goals. Therefore, energy-saving scenario is the best path to reduce carbon emission in thermal power. Energy-saving development scenario as the best choice path is based on the premise that China's economic development and population growth are in the benchmark development scenario. Of course, in order to promote the sustainable development of the thermal power industry, China should actively and continuously establish and optimize industrial policies to adapt to the high proportion of renewable energy integrated into the energy system while properly solving the reform on the coal and electricity supply side, so as to make preparations for the early realization of carbon emission peaks and the promotion of the establishment of a "clean, low-carbon, safe and efficient" energy system [54].

\section{Thermal power $\mathrm{CO} 2$ accumulaition}

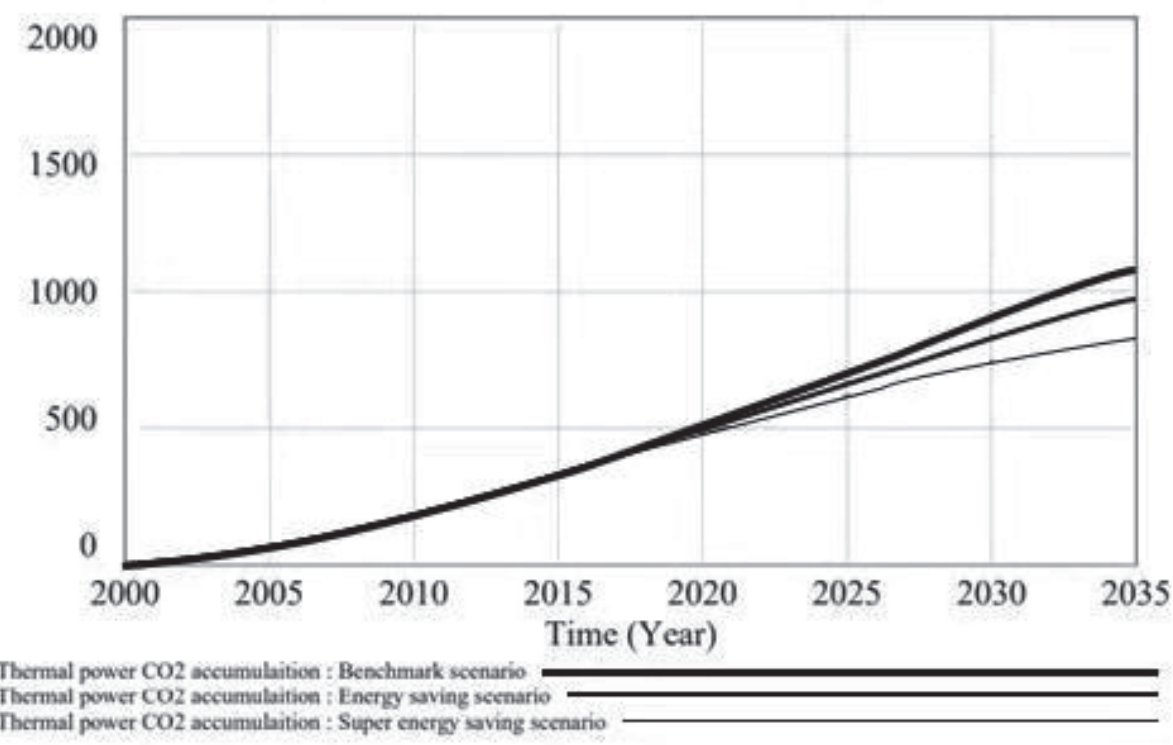

Fig. 5. With the increase of technology investment and the in-depth promotion of low-carbon policy, the cumulative amount of carbon dioxide emissions from thermal power gradually slows down and decreases in three different scenarios, which indicates that technology investment and promotion of low-carbon policies have played a certain role in thermal power carbon emissions. 


\section{Discussion}

China's thermal power carbon emission system is an extremely large, complex and changeable system, which involves many factors and belongs to complex system problems. Therefore, it is difficult to consider carefully in the research process of this paper, and some factors need to be ignored. Therefore, there are some subjectivity in selecting the indicators of the system dynamics model and determining the interrelationships among the indicators. At the same time, this paper simplifies the complexity of the model, which will cause some deviation between the simulation model and the real system.

In this paper, thermal power carbon emission system simulation modeling and policy simulation are carried out to better describe the development process and laws of thermal power carbon emissions and help the Chinese government to formulate scientific and effective thermal power carbon emission control scheme. However, how to further optimize the model in combination with other methods to better simulate the thermal power carbon emission system still needs further in-depth research. At the same time, in order to cope with the greenhouse effect and reduce the carbon dioxide emissions from thermal power, China is continuously introducing new emission reduction schemes and emission reduction mechanisms, such as carbon emissions trading, electricity carbon tax, electricity carbon financial market, etc. These successive emission reduction policies will inevitably have an impact on carbon dioxide emissions from thermal power industry. How to incorporate the above emission reduction policies into the system dynamics model and quantify them, and explore the impact of different emission reduction policies on carbon dioxide emissions from thermal power industry in China will be the research direction and hot spot in the future.

\section{Conclusions}

This paper uses System Dynamics method to model and simulate China's thermal power carbon emissions. By setting three different scenarios, the development and evolution trend of China's thermal power carbon emissions from 2017 to 2035 is dynamically simulated, and the following main conclusions are drawn:

1) Based on the test results of the system dynamics model, it is feasible to use the system dynamics model to simulate China's thermal power carbon emissions, and this model can also be used in other corresponding issues for research.

2) If there is no significant change in the system, that is, according to the current development trend, China's thermal power carbon emissions will still show an upward trend year by year in the next few years, reaching a peak of 4.228 billion tons in 2026, which is about 1.28 times of the thermal power carbon emissions in 2017.
3) Adjusting power development structure is the main way to restrain carbon emissions from thermal power industry. Control the consumption of coal, oil and other energy sources in thermal power industry, and accelerate the transformation of power structure to non-fossil energy sources. Optimization of power structure can slow down carbon emissions and air pollution, while carbon emissions of thermal power enterprises tend to account for a high proportion. Therefore, vigorously increasing the proportion of clean energy such as wind power and nuclear power and reducing the proportion of thermal power can effectively slow down the increase of carbon emissions in thermal power industry.

4) CCS technology can safely capture and store $90 \%$ of $\mathrm{CO}_{2}$ and has great potential for emission reduction. Therefore, China should vigorously support CCS technology and combine CCS technology with traditional technology to improve energy utilization efficiency and optimize management of thermal power industry so as to achieve emission reduction targets as soon as possible.

5) Through policy adjustment, the state should enhance the publicity of low carbon and environmental protection, raise people's awareness of low carbon, establish the values of low carbon and environmental protection, and conscientiously fulfill the civic responsibility of environmental protection in life, which is also of certain significance for the realization of carbon emission reduction in thermal power.

\section{Acknowledgements}

The paper is supported by National Natural Science Foundation of China (NO.71974049); The Key Project Supported by Scientific Research Fund of Hunan Provincial Education Department (20A443); Youth Talents Support Program of Hunan Province of China (2018HXQ03); Natural Science Foundation of Hunan Province of China (NO.2018JJ2336); Philosophy and Social Science Foundation of Hunan Province of China (NO.18YBQ105); and Social Science Key Breeding Project of USC (2018XZX16).

\section{Conflict of Interest}

The authors declare no conflict of interest.

\section{References}

1. DAI L.X., WANG M.Y. Study on the influence of carbon emission constraints on the performance of thermal power enterprises. Environmental Science and Pollution Research. 27 (24), 2020.

2. Environmental Pollution; Studies from North China Electric Power University Reveal New Findings on Environmental Pollution (Study on the influence of carbon 
emission constraints on the performance of thermal power enterprises). Global Warming Focus. 2020.

3. SUO X.L., SUN H.L., SUN D.H. Analysis of carbon verification calculation methods and emission reduction measures for thermal power plants. Journal of Physics: Conference Series. 1549 (5), 2020.

4. Ask the Experts: The IPCC Fifth Assessment Report. Carbon Management .5 (1),2014.

5. Structural and technological determinants of carbon intensity reduction of China's electricity generation. Environmental science and pollution research international,2020.

6. KISELEVA S.P., VISHNYAKOV YA.D., PUKHOV S.A., RAZOVSKIY YU.V., MAKOLOVA L.V. Integration of thermal power plant wastes into environmentally-oriented economic development. Ugol'. 1136 (11), 2020.

7. FENG Q., WU Z.B., ZHANG W. Carbon emissions market adjustment in the electricity supply sector: A government perspective. Journal of Cleaner Production. 275, 2020.

8. FADHILAH M.A., SAUT GURNING R.O. Cause of Electricity Supply Disruption Casuistic Assessment. IOP Conference Series: Earth and Environmental Science. 557 (1), 2020.

9. LI W., LIU L.G., WANG X.Y., QUAN C.X., ZHANG S., YU H.Y. The analysis of $\mathrm{CO}<\mathrm{sub}>2</$ sub $>$ emissions and reduction potential in china's production and supply of electric and heat power industry: A case study based on the LMDI method. Environmental Progress \&amp; Sustainable Energy. 38 (5), 2019.

10. WANG Y.S., LI S.Z., TIAN J.Y., ZHAO Z. Performance assessment of thermal power plant load control system based on covariance index. 54 (58), 2016.

11. LU Y., SHAO M., ZHENG C.H., JI H.B., GAO X., WANG Q.G. Air pollutant emissions from fossil fuel consumption in China: Current status and future predictions. Atmospheric Environment.231,2020.

12. ZHAO X.L., THOMAS P. LYON, SONG C. Lurching towards markets for power: China's electricity policy 1985-2007. Applied Energy. 94, 2012.

13. CAI L., GUO J., ZHU L. China's Future Power Structure Analysis Based on LEAP. Energy Sources, Part A: Recovery, Utilization, and Environmental Effects. 35 (22), 2013.

14. WANG Y.P., CHEN J.W. The environmental effect of capacity utilization in thermal power plants: evidence from interprovincial carbon emissions in China. Environmental science and pollution research international. 26 (29), 2019.

15. DAI L.X, WANG M.Y. Study on the influence of carbon emission constraints on the performance of thermal power enterprises. Environmental Science and Pollution Research. 27 (24), 2020.

16. SUO X.L., SUN H.L., SUN D.H. Analysis of carbon verification calculation methods and emission reduction measures for thermal power plants. Journal of Physics: Conference Series. 1549 (5), 2020.

17. SHEIKHI FINI, M. PARSA MOGHADDAM, M.K. SHEIKH-EL-ESLAMI A dynamic model for distributed energy resource expansion planning considering multiresource support schemes. International Journal of Electrical Power and Energy Systems. 60, 2014.

18. PEGGY MISCHKE, KENNETH B. KARLSSON Modelling tools to evaluate China's future energy system - A review of the Chinese perspective. Energy. 69, 2014.

19. FENG Y.Y., CHEN S.Q., ZHANG L.X. System dynamics modeling for urban energy consumption and $\mathrm{CO}_{2}$ emissions: A case study of Beijing, China. Ecological Modelling. 252, 2013.

20. ZHAO X.L., MA Q., YANG R. Factors influencing $\mathrm{CO}_{2}$ emissions in China's power industry: Co-integration analysis. Energy Policy. 57, 2013.

21. LIU L.W., ZONG H.J., ZHAO E.D., CHEN C.X., WANG J.Z. Can China realize its carbon emission reduction goal in 2020: From the perspective of thermal power development. Applied Energy. 124, 2014.

22. GUO J.X., HUANG C. Feasible roadmap for CCS retrofit of coal-based power plants to reduce Chinese carbon emissions by 2050. Applied Energy. 259, 2020.

23. DAI L.X., WANG M.Y. Study on the influence of carbon emission constraints on the performance of thermal power enterprises. Environmental Science and Pollution Research. 27 (24), 2020.

24. GUO X.P., SHI J.X., REN D.F. Coal Price Forecasting and Structural Analysis in China. 2016, 2016

25. GUO J.X., HUANG C. Feasible roadmap for CCS retrofit of coal-based powerplants to reduce Chinese carbon emissions by 2050. Applied Energy. 259, 2020.

26. Nalini Sooknanan Pillay, Darryl Chapman, Francois Geems, Sumaya Nassiep. Using System Dynamics to Determine the Impact of Electric Vehicles on Employment in the Component Manufacture Industry. INCOSE International Symposium. 30 (1), 2020.

27. GUO X.P., GUO X.D. Nuclear power development in China after the restart of new nuclear construction and approval: A system dynamics analysis. Renewable and Sustainable Energy Reviews, 57 (C), 2016.

28. VICTOR MOUTINHO, MARA MADALENO, ROULA INGLESI-LOTZ, EYUP DOGAN Factors affecting $\mathrm{CO}_{2}$ emissions in top countries on renewable energies: A LMDI decomposition application. Renewable and Sustainable Energy Reviews. 90, 2018.

29. WANG Y.N., CHEN W., KANG Y.Q., LI W., GUO F. Spatial correlation of factors affecting $\mathrm{CO}_{2}$ emission at provincial level in China: A geographically weighted regression approach. Journal of Cleaner Production. $184,2018$.

30. WANG Y.N., ZHAO M.J., CHEN W. Spatial effect of factors affecting household $\mathrm{CO}<$ sub $>2</$ sub $>$ emissions at the provincial level in China: a geographically weighted regression model. Carbon Management. 9 (2), 2018.

31. LIANG Y., NIU D.X., WANG H.C., LI Y. Factors Affecting Transportation Sector CO2 Emissions Growth in China: An LMDI Decomposition Analysis. Sustainability. 9 (10), 2017.

32. PAN C., MIN D.K. The Analysis of Carbon Emission Efficiency and Affecting Factors in China. Environmental and Resource Economics Review. 26 (2), 2017.

33. FAN F.Y., LEI Y.L., JEAN-PIERRE CORRIOU Index Decomposition Analysis on Factors Affecting EnergyRelated Carbon Dioxide Emissions from Residential Consumption in Beijing. Mathematical Problems in Engineering.2017,2017.

34. TIAN W.J., XU Z. Study of Factors Affecting Carbon Emissions - Based on an Empirical Analysis of ASEAN[J]. Journal of Resources and Ecology, 9 (5), 2018.

35. National Bureau of Statistics. http://www.stats.gov.cn/tjsj/ ndsj/2018/indexch.htm

36. National Bureau of Statistics. http://www.stats.gov.cn/tjsj/ ndsj/2010/indexch.htm

37. National Bureau of Statistics. http://www.stats.gov.cn/tjsj/ ndsj/2007/indexch.htm 
38. National Bureau of Statistics. http://www.stats.gov.cn/tjsj/ ndsj/2005/indexch.htm

39. National Bureau of Statistics. http://www.stats.gov.cn/ yearbook2001/indexC.htm

40. Energy Department, National Bureau of Statistics.http:// www.stats.gov.cn/tjsj/tjcbw/201909/t20190924_1699094. html

41. Energy Department, National Bureau of Statistics. http:// www.stats.gov.cn/tjsj/tjcbw/201303/t20130318_451533. html

42. Department of Industrial Traffic Statistics, National Bureau of Statistics and National Development and Reform Commission Energy Bureau http://www.stats.gov. cn/tjsj/tjcbw/200606/t20060602_44644.html

43. https://wenku.baidu.com/view/056d7e46bed5b9f3f90 flcb8.html

44. China Energy Research Society. https://wenku.baidu.com/ view/89f6c85351e79b896902264f.html

45. NI C.C. Potential energy savings and reduction of $\mathrm{CO}_{2}$ emissions through higher efficiency standards for polyphase electric motors in Japan. Energy Policy. 52, 2013.

46. WU J., TAN Z.F., DE G.J., PU L., WANG K.K., TAN Q.K., JU L.W. Multiple Scenarios Forecast of Electric Power Substitution Potential in China: From Perspective of Green and Sustainable Development. Processes. 7 (9), 2019.

47. GUO X.P., REN D.F., GUO X.D. A system dynamics model of China's electric power structure adjustment with constraints of PM10 emission reduction. 25 (18), 17540, 2018.

48. MUKHERJEE AGNEEV, BRUIJNINCX PIETER, JUNGINGER MARTIN A Perspective on Biofuels Use and CCS for GHG Mitigation in the Marine Sector. Science. 23 (11), 2020.
49. LOZANO MARTÍN DANIEL, VEGA MAZA DAVID, MARTÍN M. Carmen, Tuma Dirk, Chamorro César R. Thermodynamic characterization of the $\left(\mathrm{CO}_{2}+\mathrm{O}_{2}\right)$ binary system for the development of models for CCS processes: Accurate experimental $(\mathrm{p}, \rho, \mathrm{T})$ data and virial coefficients. The Journal of Supercritical Fluids. 2020.

50. RASHID MUHAMMAD IMRAN, BENHELAL EMAD, RAFIQ SIKANDER Reduction of Greenhouse Gas Emissions from Gas, Oil, and Coal Power Plants in Pakistan by Carbon Capture and Storage (CCS): A Review. Chemical Engineering \&amp; Technology. 43 (11), 2020.

51. LENA MIKHELKIS, VENKATESH GOVINDARAJAN Techno-Economic and Partial Environmental Analysis of Carbon Capture and Storage (CCS) and Carbon Capture, Utilization, and Storage (CCU/S): Case Study from Proposed Waste-Fed District-Heating Incinerator in Sweden. Sustainability.12 (15), 2020.

52. WANG Q., ZHAO M.M., LI R.R., SU M. Decomposition and decoupling analysis of carbon emissions from economic growth: A comparative study of China and the United States. Journal of Cleaner Production. 197, 2018.

53. Energy - Renewable Energy; Imperial College London Reports Findings in Renewable Energy (Does Ccs Reduce Power Generation Flexibility? a Dynamic Study of Combined Cycles with Post-combustion $\mathrm{CO}_{2}$ Capture). Ecology, Environment \&amp; Conservation. 2020.

54. JENNIE C. STEPHENS, SCOTT JIUSTO Assessing innovation in emerging energy technologies: Sociotechnical dynamics of carbon capture and storage (CCS) and enhanced geothermal systems (EGS) in the USA. Energy Policy. 38 (4), 2009. 